\title{
Gestão dos resíduos sólidos: o caso do consórcio de desenvolvimento sustentável do alto sertão na Bahia
}

\section{Solid waste management: the case of the sustainable development consortium} of alto sertão in Bahia

Thomas Leonardo Marques de Castro Leal[a] $\odot$, Rubens Jesus Sampaio[b] $[$ (])

[a] Centro Universitário UniFG, Guanambi, BA, Brasil

[b] Universidade Estadual do Sudoeste da Bahia (UESB), Vitória da Conquista, BA, Brasil

Como citar: Leal, T. L. M. C., \& Sampaio, R. J. (2021). Gestão dos resíduos sólidos: o caso do consórcio de desenvolvimento sustentável do Alto Sertão na Bahia. urbe. Revista Brasileira de Gestão Urbana, 13, e20190309. https://doi.org/10.1590/2175-3369.013.e20180123

\section{Resumo}

Passando pela gestão ambiental compartilhada entre os entes federados, este artigo tem como objetivo discutir a gestão dos resíduos sólidos domiciliares e os instrumentos de governança ambiental dos municípios que compõem um consórcio público no Semiárido Baiano. Para tanto, os dados foram coletados no Sistema Nacional de Informações sobre Saneamento (SNIS) e comparados com entrevistas realizadas com as Secretarias Municipais de Meio Ambiente, além informações levantadas in loco. Através da análise dos dados, é possível perceber que existe uma disparidade entre os dados do SNIS e os observados em campo. É perceptível ainda que nos municípios as iniciativas na gestão ambiental municipal ainda são incipientes, embora as determinações da Lei 12.305 já tenham mais de nove anos de vigência.

Palavras-chave: Resíduos sólidos. Municípios. Gestão municipal.

\section{Abstract}

Through the shared environmental management among the federated entities, this work aimed to discuss household solid waste management and the environmental governance instruments of the municipalities that compose a Public Consortium in Bahia. To this end, the data were collected from the National Sanitation Information System (SNIS) and compared with interviews conducted with the Municipal Secretariat of Environment, beyond information collected on spot. Through the analysis of the data, it was possible to realize that there is a disparity between the SNIS data and those observed in the field. It was also noticeable that the municipalities' initiatives in municipal environmental management are still incipient, although the provisions of Law 12.305 have already been in force for over nine years.

Keywords: Solid waste. Municipalities. Management.

TLMCL é professor, mestre em Ciências Ambientais, e-mail: thomasmdcl@gmail.com

RJS é professor adjunto, doutor em Desenvolvimento e Meio Ambiente, e-mail: rubensjsampaio@uesb.edu.br 


\section{Introdução}

Os primeiros passos do Brasil rumo à consolidação de uma política ambiental foram iniciados em 1934, com o Código de Águas e o Código Florestal. Contudo, em 1988, pela primeira vez, influenciada pelas reivindicações do Movimento Nacional de Reforma Urbana, abordou-se o tema meio ambiente na Constituição Federal Brasileira. A lei máxima do país aborda o tema em seu Art. 225: "Todos têm direito ao meio ambiente ecologicamente equilibrado, bem de uso comum do povo e essencial à sadia qualidade de vida, impondo-se ao poder público e à coletividade o dever de defendê-lo e preservá-lo para as presentes e futuras gerações" (Brasil, 1988).

De acordo Sampaio et al. (2014), entretanto, a utilização de matérias-primas em ritmo acelerado para a satisfação das necessidades do homem urbano tem sido um problema nos centros urbanos. Oliveira et al. (2018) salientam que, ainda hoje, especialmente nas áreas de baixa renda, há falta de saneamento que expõe a população a vários riscos para saúde e o meio ambiente. 0 instituto afirma ainda que a saúde humana é ameaçada por doenças relacionadas à falta de saneamento básico, desde a ausência de sistemas de abastecimento de água e esgotamento sanitário até a disposição inadequada de resíduos.

A gestão ambiental tem como objetivo estabelecer, recuperar e/ou manter o equilíbrio entre a natureza e sociedade (Nunes et al., 2012). 0 poder público municipal é o principal responsável por efetivação da gestão ambiental pública que, segundo Barbieri (2016), é a ação do Poder Público conduzida de acordo com a política ambiental vigente. Cabe aos municípios organizar sua política de desenvolvimento urbano, considerando os impactos de vizinhança no meio ambiente (Brasil, 2001).

0 município pode ser entendido como unidade territorial ou divisão administrativa de um estado/região, com autonomia administrativa. Para se discutir sobre a política ambiental em nível municipal, é preciso entender o processo de descentralização das políticas públicas nacionais e o conceito de gestão ambiental a nível local.

De acordo com Souza (2006), política pública é a soma das atividades do governo que irão produzir efeitos específicos em determinadas áreas, agindo diretamente ou através de delegações, influenciando a vida dos cidadãos. Barbieri (2016) define como política pública ambiental o conjunto de objetivos, diretrizes e instrumentos de ação de que o poder público dispõe para produzir efeitos desejáveis no meio ambiente.

Através do SISNAMA, foram estabelecidas as instâncias ligadas à atuação da fiscalização, coordenação e proteção do meio ambiente, desde a formulação das políticas públicas até a execução, controle e fiscalização, partindo do âmbito nacional até o local. A Figura 1 ilustra a descentralização da política ambiental nacional.

De acordo com o Conselho Nacional de Municípios (CNM, 2018), o município é a esfera do Poder Executivo mais eficaz no atendimento das demandas por um meio ambiente ecologicamente equilibrado, por estar próxima aos cidadãos em que a ação acontece, o que permite decisões mais rápidas e eficazes.

Uma das principais ferramentas no processo de gestão ambiental local é a utilização de dados e indicadores. A informação é um recurso estratégico para o planejamento e o desenvolvimento de municípios, estados, regiões e países e é necessária para conhecer e explicar a realidade de qualquer setor (Condurú \& Pereira, 2017). Desde 1995, após a publicação da Política Nacional de Saneamento, todos os municípios devem preencher os dados do SNIS (Sistema Nacional de Informação sobre Saneamento), sistema esse que compõe os instrumentos da política de saneamento. Estes dados são importantes indicadores da situação das componentes do saneamento básico no Brasil - abastecimento de água, esgotamento sanitário, limpeza urbana, drenagem urbana, manejos de resíduos sólidos e de águas pluviais, fundamentais para atender às demandas da sociedade em relação a um saneamento básico de qualidade. 


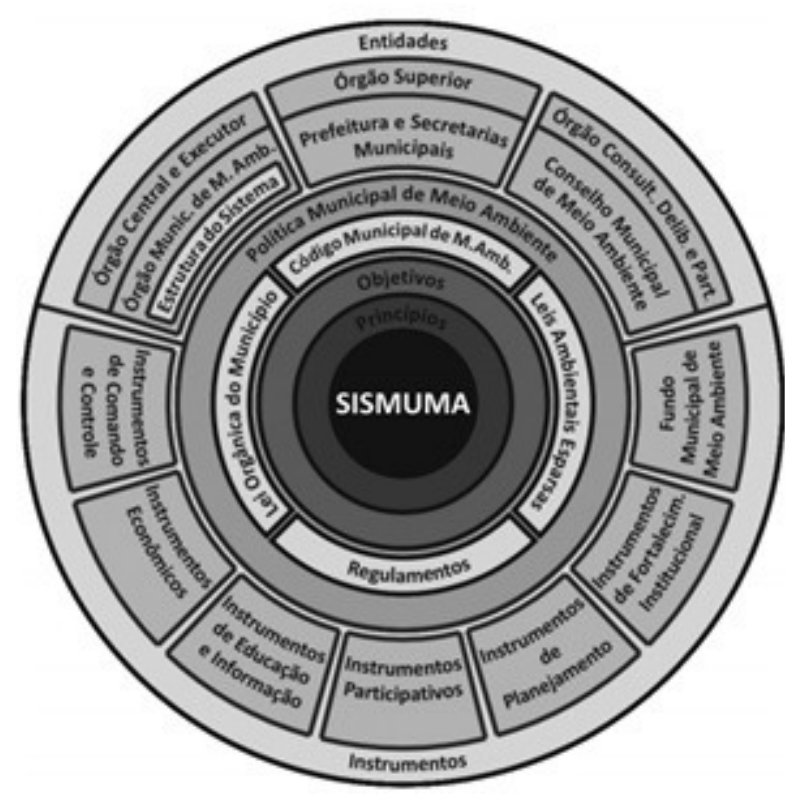

Figura 1 - Representação gráfica do SISMUMA. Fonte: Ávila \& Malheiros (2012).

Partindo do pressuposto do papel do Estado como agente promotor de políticas públicas voltadas para um ambiente ecologicamente equilibrado, este artigo visa caracterizar e contextualizar o SISMUMA e o gerenciamento dos resíduos dos municípios do Consórcio de Desenvolvimento Sustentável do Alto Sertão (CDS Alto Sertão), discutindo a importância destes para a gestão ambiental em nível municipal e regional.

\section{Aspectos metodológicos}

Metodologicamente, o trabalho assume, primeiramente, a abordagem qualitativa e se utiliza da observação direta e entrevistas semiestruturadas para avaliar o arcabouço institucional nos municípios brasileiros para a gestão e governança ambiental. Dados do Perfil dos Municípios Brasileiros do Instituto Brasileiro de Geografia e Estatística (IBGE, 2014) foram utilizados para discussão.

Num segundo momento, uma avaliação quantitativa a partir da análise dos dados do SNIS. Este organiza em forma de tabela as informações fornecidas pelos municípios, que vão desde informações financeiras até dados sobre números de catadores e indicadores sobre os serviços prestados. Após análise dos dados disponíveis, foram selecionados alguns campos.

A seleção das informações foi ao encontro do objetivo, avaliando apenas as informações pertinentes aos resíduos domiciliares. Cada conjunto de dados avaliados possui um campo, um código, referente ao item em questão. Foram organizadas e avaliadas, sendo utilizados os campos disponíveis dos conjuntos de dados sobre informações e indicadores de dados financeiros, de resíduos domiciliares e públicos, destinação final e planos municipais.

\section{Área de estudo}

Como a elaboração do plano municipal de gestão integrada de resíduos sólidos é condição para os municípios terem acesso a recursos da União, a formação de consórcios com a finalidade de soluções consorciadas intermunicipais para a gestão dos resíduos sólidos tornou-se uma opção tangível e viável. Após a Lei 11.107/2005, que dispõe sobre normas gerais de contratação de consórcios públicos e dá outras providências, o número de consórcios em todo o Brasil começou a crescer. Seguindo esta 
tendência, foi formado o CDS Alto Sertão, que hoje é constituído de 16 municípios, conforme mostra a Figura 2.

O CDS Alto Sertão foi criado através da Lei no 713, de 22 de março de 2013 que Ratifica Protocolo de Intenções para a constituição do consórcio. Na época, foram subscritores do protocolo de intenções 25 municípios, contudo somente 13 chegaram a constituí-lo, ingressando mais três em 2017.

Dentre os seus objetivos encontram-se as diversas demandas regionais de interesse público. A Lei 713/2013 detalha as finalidades, entre elas a gestão associada de serviços públicos de saneamento básico, além da elaboração de "[...] estudos técnicos para informar o licenciamento ambiental e urbanístico por consorciado" (Guanambi, 2013).

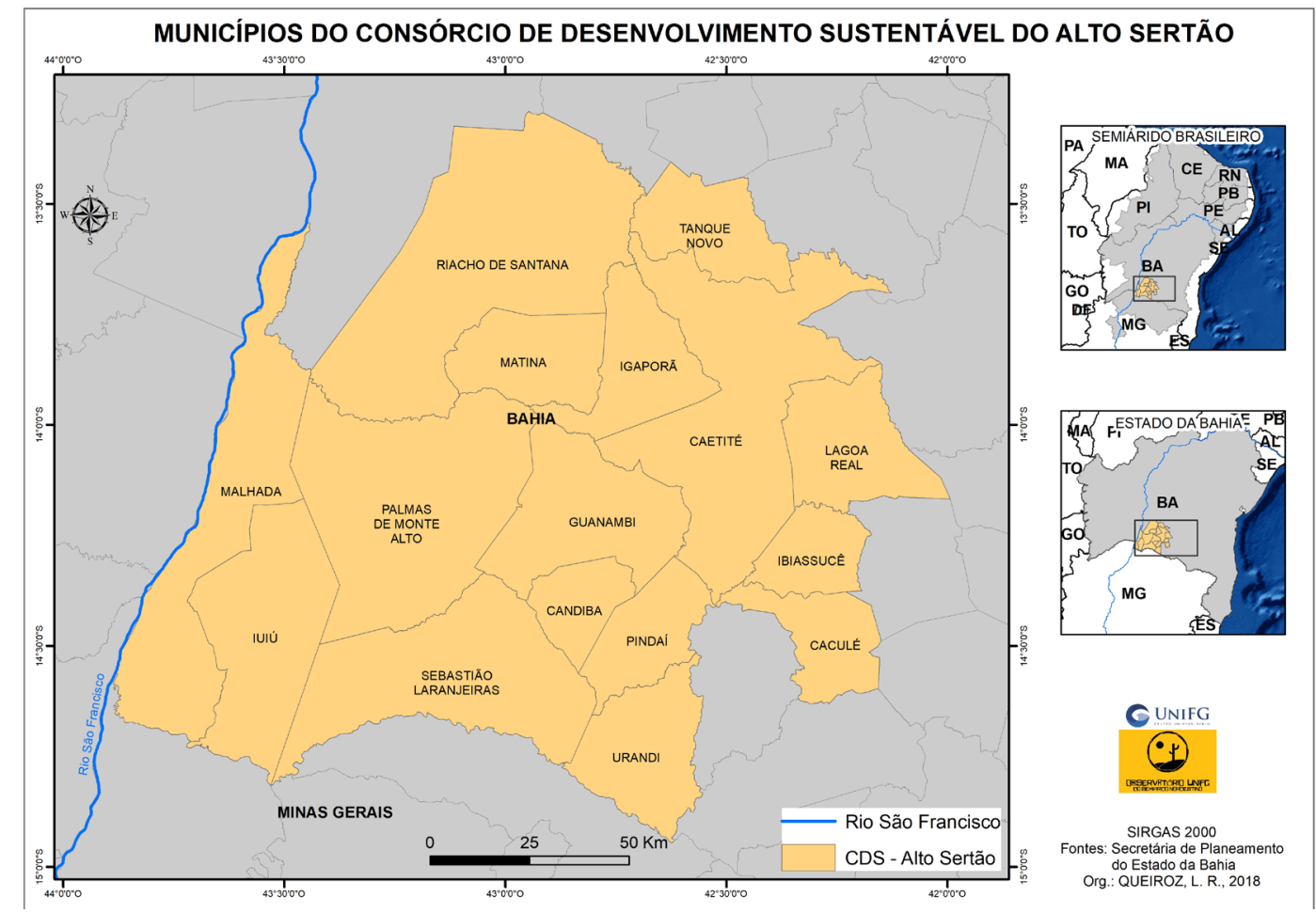

Figura 2 - Municípios que compõe o CDS Alto Sertão. Fonte: Bahia (2015).

\section{Resultados e discussões}

A primeira observação a ser realizada é a ausência de dados ou não atualização dos dados no SNIS por parte de alguns municípios. Cidades como Caculé, Ibiassucê, Igaporã, Malhada e Tanque Novo nunca preencheram ou realizaram o último preenchimento da plataforma há mais de dez anos. Assim, foram excluídos da análise para evitar distorção dos dados avaliados.

A existência de uma Política Municipal de Saneamento Básico, do Plano Municipal de Saneamento Básico (PMSB) e de um Plano Municipal de Gestão Integrada Resíduos Sólidos (PMGIRS) é essencial para o bom gerenciamento do Resíduos Sólidos Urbanos (RSU). O PMGIRS pode estar inserido no Plano de Saneamento Básico integrando-se com os planos de água, esgoto, drenagem urbana e resíduos sólidos, previstos na Lei no 11.445 , de $2007^{1}$ (Brasil, 2007a). Estas informações foram verificadas nos Campos P0001, P0028 e P0048 do SNIS.

De acordo com o SINIR (2019), apenas 37\% das cidades estudadas elaboraram o PMGIRS e, segundo o SNIS (2019), nenhuma delas possui o PMSB, conforme Figura 3.

\footnotetext{
${ }^{1}$ Deve ser respeitado o conteúdo mínimo definido em ambos os documentos legais.
} 


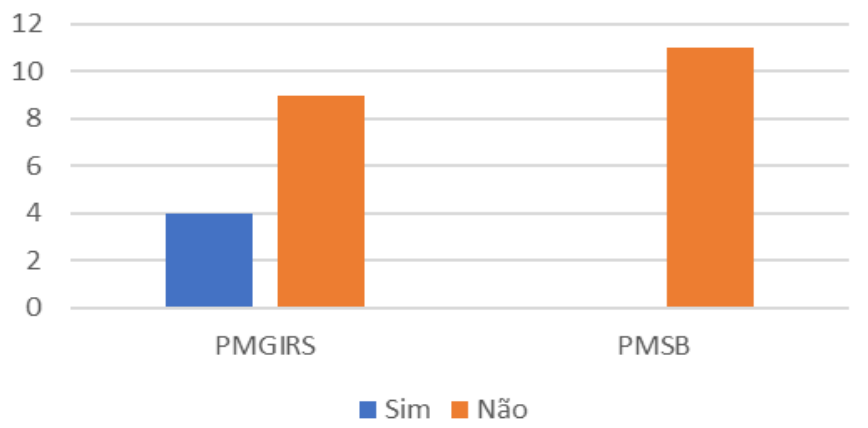

Figura 3 - Municípios que elaboraram o PMGIRS e PMSB. Fonte: SNIS (2019) e SINIR (2019).

A PMSB é importante, pois é a legislação norteadora dos que observam os princípios de universalização, integralidade, igualdade, participação e controle social, titularidade municipal, gestão pública e articulação ou integração institucional, previstos na Lei no. 11.445/2007. Engloba, até certo ponto, a problemática da disposição inadequada de resíduos sólidos, já que tal prática implica em prejuízos à saúde humana, isto porque locais onde há acúmulo de resíduos sólidos domiciliares, sem nenhum controle, atraem vetores ou organismos transmissores de doenças.

Em decorrência, os planos de resíduos sólidos devem abranger todo o gerenciamento dos resíduos, desde a geração até a disposição final ambientalmente adequada, passando pela responsabilização do setor público, titular ou concessionária que preste o serviço, do consumidor, do cidadão e do setor privado na adoção de soluções que minimizem ou ponham fim aos efeitos negativos para a saúde pública e para o meio ambiente em cada fase do "ciclo de vida" dos produtos (Brasil, 2010).

Já o PMGIRS fornece informações necessárias para o bom planejamento das ações a serem tomadas na gestão adequada dos resíduos (dados como a origem, o volume, caracterização dos resíduos, composição gravimétrica, sazonalidade de geração, tipos de resíduos gerados etc.; todos dados importantíssimos).

A CNM (2016) realizou uma pesquisa com 75\% dos municípios brasileiros sobre a gestão municipal dos resíduos e um dos questionamentos versava sobre a elaboração do PMGRS. De acordo com os dados coletados, 43,8\% estavam em processo de elaboração e 19,2\% sequer haviam iniciado o processo.

Dentre as dificuldades citadas, a que chamou mais atenção foi a de captação de recursos para elaboração do plano ( $22 \%$ dos municípios), seja recurso federal, estadual ou qualquer outro fundo. A CNM (2016) perguntou aos gestores que haviam finalizado o plano $(36,3 \%)$ qual foi o custo total de elaboração do documento e 43,6\% responderam que o valor gasto ficou abaixo de $\mathrm{R} \$ 25.000,00$. Além disso, 70\% afirmaram ter utilizado recursos próprios para elaboração deste.

\section{Custo com manejo de resíduos sólidos}

A elaboração do PMGIRS é condição para o Distrito Federal e os municípios terem acesso a recursos da União, ou por ela controlados, destinados a empreendimentos e serviços relacionados à limpeza urbana e ao manejo de resíduos sólidos, ou para serem beneficiados por incentivos de entidades federais de crédito ou fomento para tal finalidade (Brasil, 2010).

Por não possuírem o PMGRIS, os municípios não tiveram acesso a recursos federais para aplicação no setor, segundo informações disponíveis no SNIS; todas as despesas com manejo ${ }^{2}$ de RSU são custeadas com as receitas municipais (Campo FN224). Para os municípios, a média da despesa total, todos os tipos de resíduos, foi de $\mathrm{R} \$ 1.849 .989,75$. A Figura 4 demonstra o quantitativo (Campo FN220).

\footnotetext{
${ }^{2}$ Limpeza urbana e manejo de resíduos sólidos: conjunto de atividades, infraestruturas e instalações operacionais de coleta, transporte, transbordo, tratamento e destino final do lixo doméstico, como também do lixo originário da varrição e limpeza de logradouros e vias públicas (Brasil, 2007b).
} 


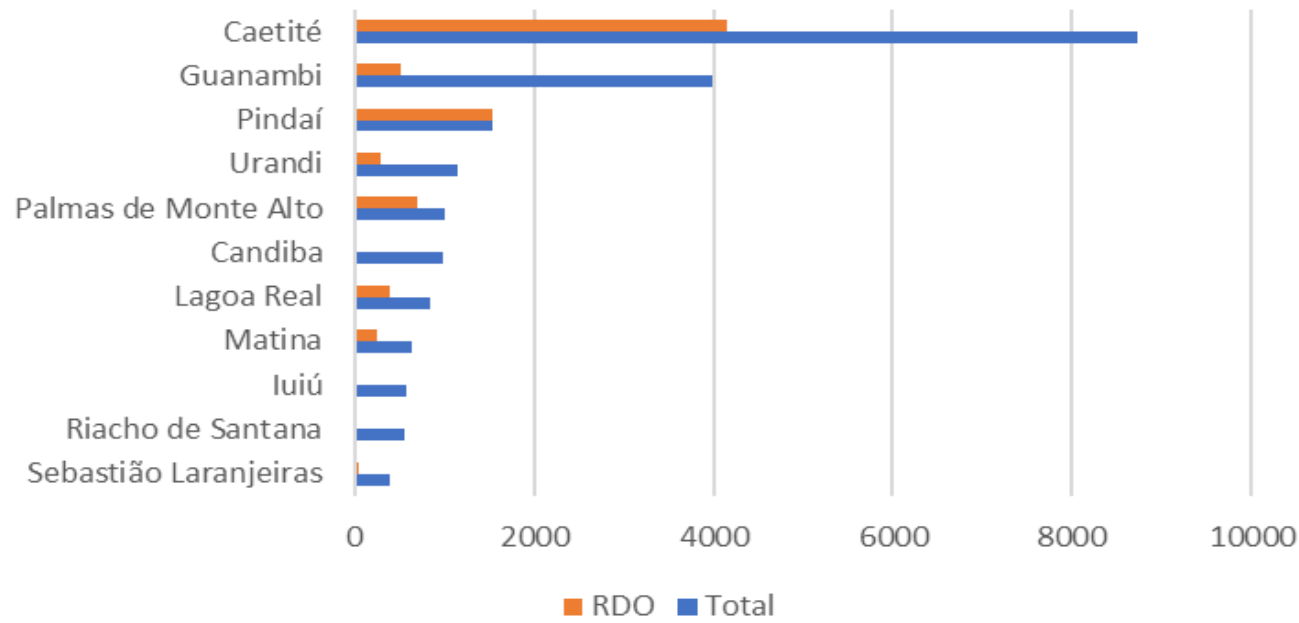

Figura 4 - Despesa total anual com serviços de manejo total de resíduos e de RDO. Fonte: SNIS (2019).

As cidades de Candiba, Iuiú e Riacho de Santana não informaram o percentual gasto com resíduos domiciliares, informando apenas o total. Já a cidade de Pindaí forneceu dados de que todos os recursos vão apenas para o gerenciamento dos resíduos domiciliares. Quando questionado, o representante da secretaria de meio ambiente de Pindaí informou que no ano em questão, 2007, algumas informações foram preenchidas incorretamente, pois o gestor da época não era da área e desconhecia tais informações.

A análise dos custos totais pode estar ligada à terceirização dos serviços nos municípios. De acordo Felisaki \& Stoffel (2014), o custo estimado com a execução do serviço de manejo dos resíduos domiciliares pelo poder público é superior ao custo gerado pela terceirização do serviço. Em seu estudo, os autores perceberam que o maior valor pago pela administração pública do município para a empresa terceirizada durante o período estudado representa aproximadamente $70 \%$ do valor anual que seria gasto para a execução direta do serviço pela prefeitura. Dados do SINIR, mostram que em 70,58\% das cidades é a iniciativa privada que é agente executor da gestão dos resíduos municipais, diferentemente da região estudada.

Dentro do conjunto de informações gerais foi verificado qual cidade realiza terceirização dos serviços de coleta de resíduo domiciliar (Campo GE202). A terceirização tem impacto direto sobre o orçamento das cidades. Apenas as cidades de Guanambi e Riacho de Santana realizam terceirização das atividades de manejo e possuem custos menores de gerenciamento.

Contudo, Rodrigues et al. (2016) afirmaram que altos custos de transação indicam que o mercado está sendo utilizado de forma ineficiente.

Diferente, do que a literatura microeconômica neoclássica propõe, no caso dos resíduos sólidos, nas capitais brasileiras, a existência do setor privado na operação dos serviços tende a trazer pressões de aumento dos custos dos serviços oferecidos, e não ao contrário, como se costuma atribuir a maior eficiência do setor privado sobre o setor público, em termos de produtividade e eficiência. (Rodrigues et al., 2016, p. 134).

Apesar da dificuldade de determinar as influências sobre os orçamentos municipais, a grande preocupação trata-se dos custos que estes municípios possuem; alguns locais chegam a gastar (Campo FN223) cerca de 8\% do orçamento anual com o manejo de resíduos.

A quantidade de resíduos domiciliares e de varrição gerados pelos municípios diariamente é, em média, 1,21 kg/hab.dia (Campo IN021), com um total anual de 84,283 ton/ano de resíduos (Campo C0119) e nenhuma das prefeituras cobram pelos serviços de coleta regular, transporte e destinação final de RSU (Campo FN201). 


\section{Coleta e destinação final de resíduos domiciliares}

A taxa de cobertura do serviço de coleta dos resíduos domiciliares da população urbana do município também foi analisada. De acordo a ABRELPE (2016), a média da taxa de coleta na Região Nordeste é de 79,06\%, a menor do Brasil. Para os municípios analisados, a média encontra-se levemente elevada, $88,7 \%$, conforme Figura 5.

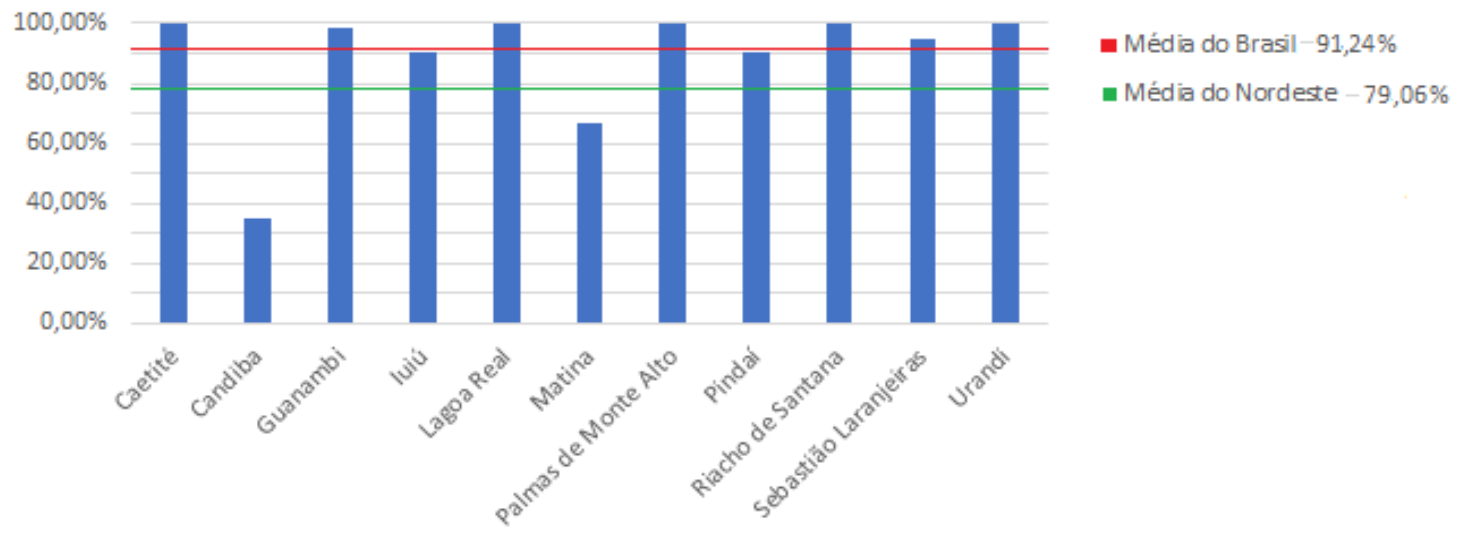

Figura 5 - Índice de cobertura, em percentual, do serviço de coleta de resíduos. Fonte: SNIS (2019) e ABRELPE (2016).

Vale destacar ainda que a cidade de Candiba, por exemplo, realiza o serviço para menos de $50 \%$ população, estando bem abaixo das outras cidades. Em uma entrevista com o secretário de Meio Ambiente buscou-se entender os motivos para tal índice. Ele afirmou que os dados fornecidos estavam incorretos e que toda a população urbana é atendida pela coleta regular. 0 entrevistado levantou as possibilidades de que, por não haver coleta diariamente, este índice possa ter caído, ou de que a equipe do gestor anterior preencheu incorretamente.

Em se tratando da destinação final destes resíduos coletados, de acordo o SINIR (2019), os destinos mencionados pelas cidades foram lixão, aterro controlado ou não declararam. Dos 11 municípios avaliados, seis (55\%) afirmaram ter um lixão como forma de destinação final, dois (18\%) afirmaram possuir um aterro controlado e três (27\%) não declararam as informações.

As cidades que disseram possuir um aterro controlado como forma de destinação final foram Riacho de Santana e Urandi. As cidades que não declaram foram Caetité, Guanambi e Iuiú. Conforme afirmam Mancini et al. (2012), aterro controlado é um nome pomposo dado a uma forma errônea de destinação final do ponto de vista ambiental e de saúde pública. Em uma visita realizada in loco aos locais de destinação final destas cidades, foi possível constatar que são todos lixões (Figuras 6 e 7).

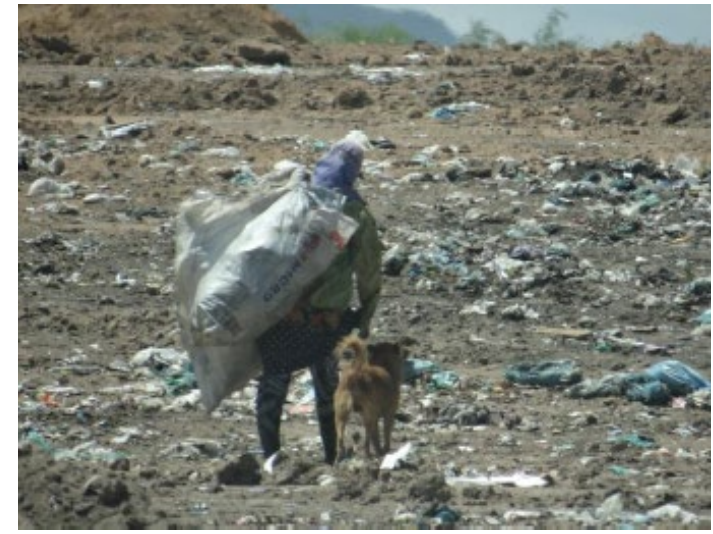

Figura 6 - Catadores no lixão da cidade de luiú. Fonte: Arquivo pessoal (2018). 


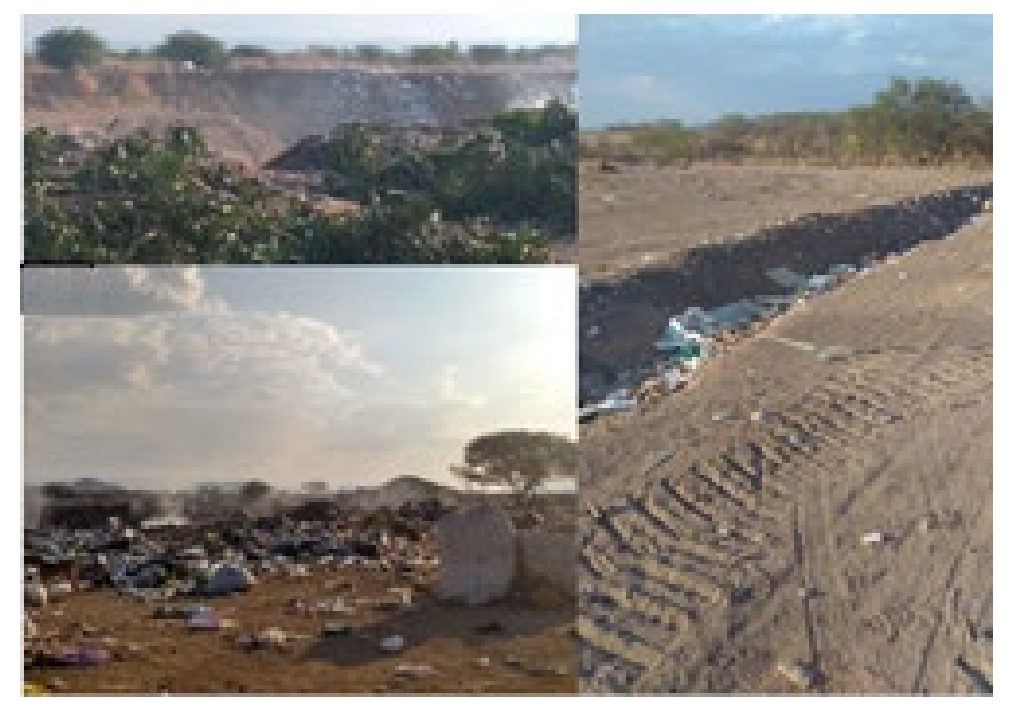

Figura 7 - Fotos do lixão de Guanambi. Fonte: Arquivo pessoal (2018).

\section{Coleta seletiva}

Em relação à coleta seletiva e aos catadores de materiais recicláveis, os dados disponíveis foram organizado e estão relacionados na Figura 8.

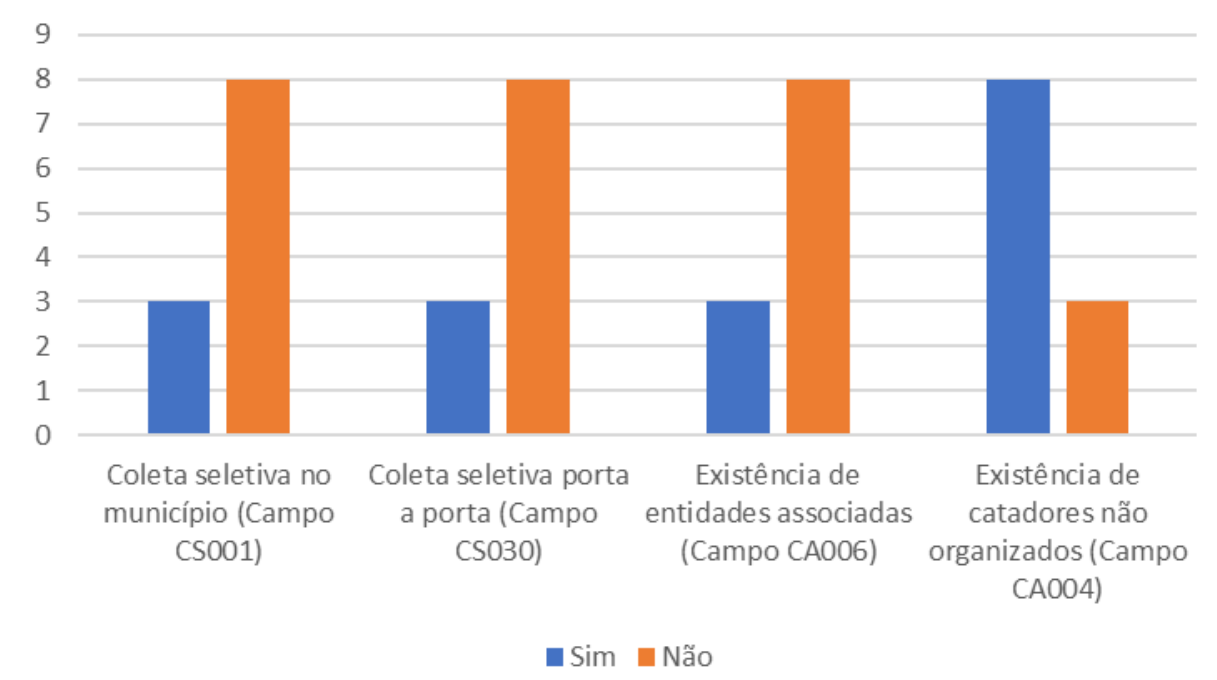

Figura 8 - Dados sobre coleta seletiva nas cidades. Fonte: SNIS (2019).

A partir da análise dos dados é possível perceber que a maior parte dos municípios possui catadores não organizados, na informalidade. Ainda pelos dados disponíveis, nota-se que a coleta seletiva acontece em menos de $30 \%$ das cidades analisadas. Essas duas varáveis em conjunto mostram que a maioria dos catadores realizam a coleta sem as devidas orientações/condições, muitas vezes coletando o material do local de disposição final, o lixão.

Mesmo representando um elo fundamental da cadeia de reciclagem brasileira, estes encontram-se expostos a condições de trabalho insalubres, associadas a uma exclusão social em um entorno social hostil (Souza et al., 2012).

Esta condição de informalidade faz com este catador esteja à mercê de atravessadores, um intermediário, que compra o material dos catadores para revender às grandes indústrias de reciclagem. Por não estarem organizados, os catadores não conseguem uma quantidade mínima que compense o 
transporte e, por consequência, não conseguem vender o material. De acordo com o SINIR (2019), recupera-se apenas 1,89\% dos recicláveis (Campo IN031) em relação à quantidade de resíduos no Estado.

Apesar da PNRS trazer em seus objetivos, Art. $7^{\circ}$ inciso XII, a "integração dos catadores de materiais reutilizáveis e recicláveis nas ações que envolvam a responsabilidade compartilhada pelo ciclo de vida dos produtos", os catadores são tidos pela sociedade, e mesmo pelos próprios catadores, como destituídos de importância (Severi, 2014).

Dentre as principais contribuições dos catadores na mitigação de impactos ambientais, Souza et al. (2012) destacam o aumento da vida útil dos aterros sanitários, a diminuição da poluição decorrente da disposição incorreta desses resíduos e a redução da extração de matéria-prima virgem, decorrente da integração do material reciclado como matéria-prima secundária na cadeia produtiva. Além disso, quando se consideram os índices de reciclagem do país, estima-se que a atividade tem sido capaz de gerar benefícios econômicos ambientais entre $\mathrm{R} \$ 1,4$ bilhão e $\mathrm{R} \$$ 3,3 bilhões anuais (Severi, 2014).

\section{Gestão ambiental municipal}

$\mathrm{Na}$ área ambiental, cabe aos municípios suplementar as legislações das demais esferas, federal e estadual, e legislar sobre os interesses locais. O Sistema Municipal de Meio Ambiente (SISMUMA) é o conjunto de órgãos e entidades do município que são responsáveis pela preservação, conservação, proteção, defesa, melhoria, recuperação e controle do meio ambiente e uso adequado dos recursos ambientais do município (Ávila \& Malheiros, 2012) e é composto por normas e órgãos ambientais municipais, como um conselho e um fundo municipal de meio ambiente, plano diretor, zoneamento ambiental, código de posturas, lei de parcelamento, uso e ocupação do solo, plano de gerenciamento integrado de resíduos sólidos, dentre outros.

Assim, a política municipal de meio ambiente é um conjunto de legislações que podem apresentar diferentes formatos, não excludentes, como lei orgânica municipal, plano diretor urbano, código municipal de meio ambiente, entre outros. O IBGE (2014) verificou que 65,5\% dos 5.570 municípios brasileiros apresentam algum tipo de legislação ambiental, mas que esse número é menor entre as cidades com menos 20 mil habitantes, chegando a 64,9\%. As Figuras 9 e 10 apresentam uma representação da atual estrutura ambiental das cidades estudadas.

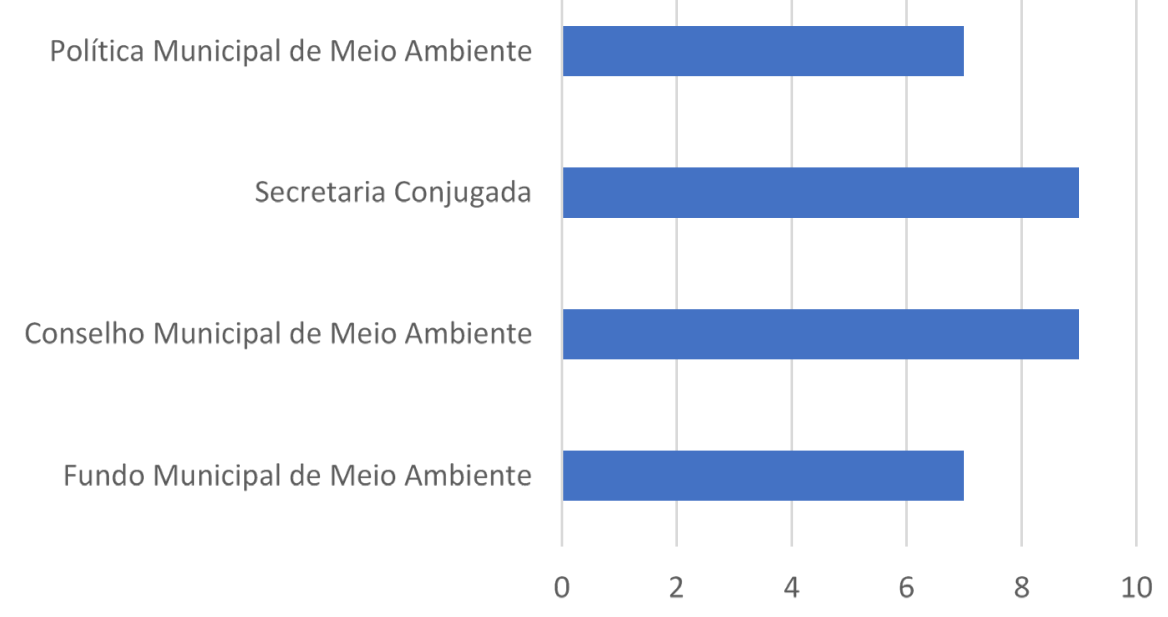

Figura 9 - Caracterização do SISMUMA dos municípios do CDS. 


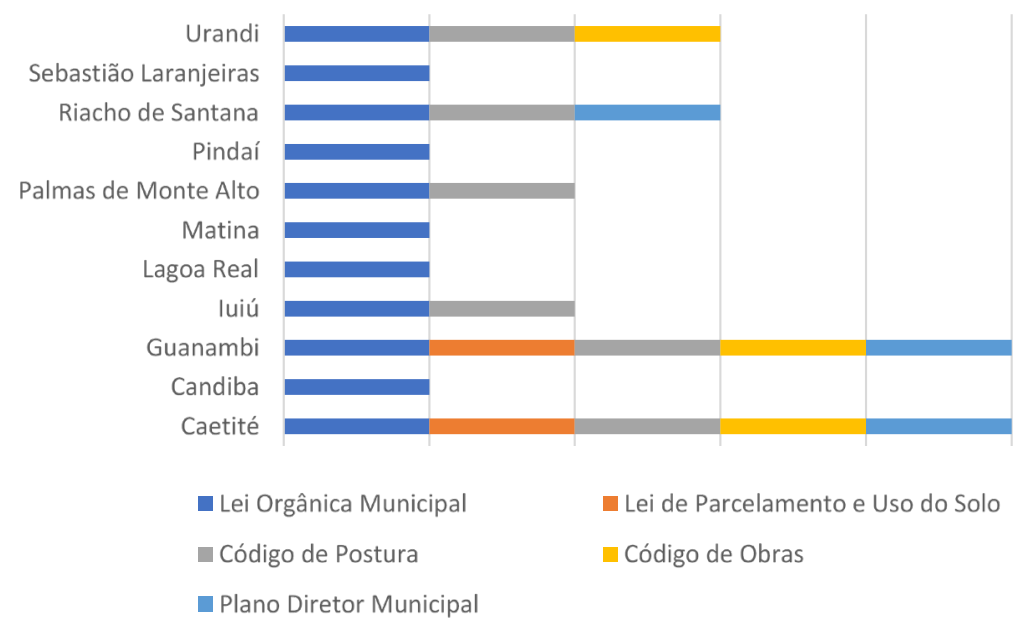

Figura 10 - Legislação dos municípios que contemplam o tema do meio ambiente.

Dentre os municípios estudados, é possível perceber que a realidade é muito próxima da que foi relatada. Apenas 63,3\% possuem legislações voltadas ao meio ambiente. A ausência de legislação específica enfraquece ações do poder público municipal na preservação, conservação, defesa, melhoria, recuperação e controle do meio ambiente. De acordo Ávila \& Malheiros (2012), a estruturação de uma política municipal de meio ambiente não passa apenas pela criação de novas normas ambientais, mas também pela necessidade de atualização/revisão das políticas urbanas municipais, como plano diretor, da lei de uso e ocupação do solo, do código de obras, de postura, tributário etc. 0 gráfico anterior mostra quais legislações municipais contemplam a área ambiental em seu texto.

Todas as cidades possuem pelo menos um artigo em sua lei orgânica que trate sobre o meio ambiente, mas nem todas possuem pena para infratores em seu código de postura. Somente três cidades possuem plano diretor urbano, mas só as cidades que possuem mais de 20.000 habitantes e são obrigadas a ter. A lei de parcelamento e uso do solo tem por objetivo buscar o adequado ordenamento territorial, estabelecendo política de controle e fiscalização da ocupação de áreas e somente duas cidades possuem tal legislação. Já o código de obras é uma legislação complementar que estabelece exigências para execução de novas obras na cidade, exigindo, muitas vezes, um estudo de impacto ambiental e estudo de impacto de vizinhança.

Uma das principais entidades que compõem o SISMUMA e vem complementar a política municipal é o Conselho Municipal de Meio Ambiente. Este órgão possui caráter deliberativo, normativo ou consultivo, estabelecido pelo SISNAMA, Lei 6.938/1981, Art. 6 ${ }^{\circ}$ que age em âmbito local (Brasil, 1981). É uma importante ferramenta de participação, contando com representações de diversas esferas, como entidades da indústria, do comércio, de serviços, da agricultura, universidade, instituições de pesquisa e sociedade civil organizada; é um espaço de participação social e mediação de conflitos.

A participação da sociedade local nestes conselhos permite identificar as demandas e problemas emergentes enfrentados, levando-os diretamente ao poder público. De acordo com Brasil et al. (2012), esse canal de participação obrigara o Estado a negociar suas propostas com outros grupos sociais, dificultando a atual confusão entre interesse público e interesses de grupos específicos.

Scardua \& Bursztyn (2003) defendem que a participação social é essencial para que ocorra a democracia participativa e representativa e o governo deve ser imparcial e intervir no processo de forma a diminuir as distorções econômicas inerentes ao sistema da maneira mais transparente possível.

Segundo IBGE (2014), aproximadamente 68\% das cidades brasileiras possuem conselhos implementados. Em relação à região estudada, apenas duas cidades não possuem conselho municipal. De acordo Philippi et al. (2004), alguns fatores podem atrapalhar o bom funcionamento deste conselho, como falta de fortalecimento, inoperância, manipulação, desarticulação, falta de legitimidade, ausência de funcionalidade, legitimidade das representações, criação apenas com o intuito de angariar recursos, 
conflito de interesses entre o setor público e privado, função estritamente consultiva e falta de participação popular.

Para efetivar as decisões referentes ao meio ambiente e para uma fiscalização efetiva, é fundamental a construção de uma estrutura que efetue a gestão do meio ambiente no âmbito municipal, que é a Secretaria Municipal de Meio Ambiente. Estes órgãos são os responsáveis pela gestão ambiental e pela execução de programas, projetos e pelo controle e fiscalização, sendo vitais ao bom funcionamento dos SISMUMA. Muitas vezes as questões ambientais acabam sendo tratadas em conjunto com outras áreas, criando pastas conjugadas. Dos 11 municípios entrevistados, 2 apresentam uma secretaria exclusiva para meio ambiente, o restante apresenta uma secretaria conjugada com agricultura e/ou abastecimento. De acordo o IBGE (2014), até 2013, apenas $27,12 \%$ das cidades possuíam secretaria municipal exclusiva para meio ambiente.

Já o Fundo Municipal de Meio Ambiental é responsável pela captação e pelo gerenciamento dos recursos financeiros, valores estes arrecadados através de multas aplicadas, da cobrança de taxas pelo licenciamento ambiental e saldos resultantes de contribuições, convênios e doações, ou provenientes de contratos com instituições e fundos, conforme prevê a Lei 9.605/1998, de crimes ambientais. 0 fundo tem como objetivo planos, programas, projetos e ações de iniciativas públicas e privadas, uso racional e sustentável dos recursos naturais, controle, fiscalização, defesa e recuperação do meio ambiente e a educação ambiental.

Em 2013, de acordo IBGE (2014), 2.386 (42,8\%) municípios do país dispunham de fundo de meio ambiente. Dos municípios estudados, apenas $63,6 \%$ possuem um fundo municipal de meio ambiente ativo. A ausência de fundo com esta finalidade fragiliza as ações do poder público local na promoção de um ambiente ecologicamente equilibrado. Ainda segundo o IBGE, os recursos desse fundo podem:

[...] ser utilizados por órgãos das administrações direta e indireta do próprio município, organizações não governamentais, organizações da sociedade civil de interesse público, organizações de base, como sindicatos, associações de produtores, associações de reposição florestal, entre outras, desde que se configurem como organizações sem fins lucrativos. (IBGE, 2014, p. 15).

Ainda fazem parte desta boa gestão, os recursos humanos, servidores deste órgão ambiental. O IBGE (2014) verificou que, em 2013, existiam pouco mais de 61 mil funcionários ocupados na área de meio ambiente dos municípios brasileiros e apenas $45,5 \%$ eram de regime estatutário, ou seja, concursados. Isso acaba provocando uma alta rotatividade de funcionários, gerando descontinuidade às políticas e programas da área. A região estudada apresentou índices semelhantes, menos de $50 \%$ dos responsáveis pelas secretarias com vínculo de servidores estatutários.

Outro fator, são os profissionais contratados ou nomeados sem formação específica na área, o que acaba refletindo negativamente na gestão ambiental do município. No âmbito do consórcio, menos de $50 \%$ dos gestores locais possuem formação específica na área ambiental.

\section{Considerações finais}

O não preenchimento ou o preenchimento incorreto dos dados no SNIS é um fator importante a ser observado. Os dados fornecidos são essenciais para o planejamento das políticas públicas voltadas para a área. A ausência de dados mascara a necessidade de investimentos ou readequações das ações. Além disso, o não preenchimento do SNIS torna o município inadimplente, o que pode comprometer no repasse de emendas parlamentares, empréstimos, projetos aprovados nas áreas das temáticas.

Os municípios em questão ainda estão tomando as primeiras iniciativas no tocante à governança ambiental. Há carências de capacidade técnica, estruturação de órgãos, conselhos, legislações e fundos, sobretudo para o real funcionamento destes elementos.

É possível perceber ainda que, embora as determinações da Lei 12.305 já tenham mais de nove anos de vigência, nenhum dos 11 municípios estudados está em conformidade com a legislação vigente. A não 
adequação das cidades à PNRS é grave, pois deixa a região suscetível a problemas ambientais e sociais de grande magnitude.

É urgente a elaboração de um plano intermunicipal que dê as diretrizes necessárias para o estabelecimento de ações concretas no tocante à gestão e ao gerenciamento dos RSU. Todavia, salientase que esta pesquisa não teve o intuito de responder a todas as questões no que se refere à gestão de resíduos sólidos municipais. Por isso, as realizações de novas pesquisas nesta temática aprofundariam os estudos, desde o levantamento de dados primários, como composição gravimétrica dos resíduos, até a determinação de áreas para implementação dos aterros consorciados.

\section{Referências}

Associação Brasileira de Limpeza Pública e Resíduos Especiais - ABRELPE. (2016). Panorama dos resíduos sólidos no Brasil 2016. Recuperado em 27 de outubro de 2019, de

http://www.abrelpe.org.br/Panorama/panorama2016.pdf

Ávila, R. D., \& Malheiros, T. F. (2012). O Sistema Municipal de Meio Ambiente no Brasil: avanços e desafios. Revista Saúde e Sociedade, 21(Supl. 3), 33-47.

Bahia. Superintendência de Estudos Econômicos e Sociais da Bahia - SEI. Secretaria de Planejamento - SEPLAN. (2015). Atlas dos territórios de identidade. Salvador. Recuperado em 27 de outubro de 2019, de https://www.sei.ba.gov.br/index.php?option=com_content\&view=article\&id=2000\&Itemid=284

Barbieri, J. C. (2016). Gestão ambiental empresarial: conceitos, modelos e instrumentos (4. ed.). São Paulo: Saraiva.

Brasil. (1981, 31 de agosto). Lei n. 6.938, de 31 de agosto 1981. Dispõe sobre a Política Nacional de Meio Ambiente, seus fins e mecanismos de formulação e aplicação, e dá outras providências. Brasília: Diário Oficial da União.

Brasil. (1988, 5 de outubro). Constituição da República Federativa do Brasil. Brasília: Diário Oficial da União.

Brasil. (2001, 10 de julho) Lei n. 10.257 de 10 julho de 2001. Regulamenta os arts. 182 e 183 da Constituição Federal, estabelece diretrizes gerais da política urbana e dá outras providências. Brasília: Diário Oficial da União.

Brasil. (2007a, 5 de janeiro). Lei $n$. 11.445, de 5 de janeiro de 2007. Estabelece as diretrizes nacionais para o saneamento básico, cria o Comitê Interministerial de Saneamento Básico. Brasília: Diário Oficial da União.

Brasil. (2007b, 17 de janeiro). Decreto n. 6.017, de 17 de janeiro de 2007. Regulamenta a Lei no 11.107, de 6 de abril de 2005, que dispõe sobre normas gerais de contratação de consórcios públicos. Brasília: Diário Oficial da União.

Brasil. (2010, 2 de agosto). Lei n. 12.305, de 2 de agosto de 2010. Institui a Política Nacional de Resíduos Sólidos; altera a Lei no 9.605, de 12 de fevereiro de 1998 e dá outras providências. Brasília: Diário Oficial da União.

Brasil, F., Silva, G., Carneiro, R., \& Almeida, M. (2012). Gestão democrática das cidades e instituições participativas: tendências no contexto brasileiro recente. Economia Global e Gestão, 17(1), 117-134. Recuperado em 27 de outubro de 2019, de http://www.scielo.mec.pt/scielo.php?script=sci_arttext\&pid=S0873-

74442012000100008\&lng=pt\&tlng=pt.

Condurú, M. T., \& Pereira, J. A. R. (2017). Gestão da informação em saneamento básico no Estado do Pará sob o enfoque do ciclo informacional. Engenharia Sanitaria e Ambiental, 22(6), 1225-1232.

http://dx.doi.org/10.1590/s1413-41522017145238.

Confederação Nacional dos Municípios - CNM. (2016). Gestão municipal de resíduos sólidos. Brasília, DF.

Recuperado em 27 de outubro de 2019, de https://www.cnm.org.br/biblioteca/exibe/2596

Confederação Nacional dos Municípios - CNM. (2018). Mapeamento dos consórcios públicos brasileiros. Brasília, DF. Recuperado em 27 de outubro de 2019, de https://www.cnm.org.br/biblioteca/exibe/3646

Felisaki, F., \& Stoffel, J. A. (2014) A terceirização da coleta do lixo urbano: o caso de Nova Esperança - PR. In Anais do III Congresso Nacional de Pesquisa em Ciências Sociais Aplicadas. Francisco Beltrão: UNIOESTE. Recuperado em 27 de outubro de 2019, de http://cac- 
php.unioeste.br/eventos/conape/anais/iii_conape/Arquivos/Artigos/Artigoscompletos/CIENCIASECONOMICAS/ 3.pdf

Guanambi. (2013). Lei municipal n. 713, de 22 de março de 2013. Ratifica Protocolo de Intenções para a constituição do Consórcio. Guanambi: Diário Oficial do Município.

Instituto Brasileiro de Geografia e Estatística - IBGE. (2014). Perfil dos municípios brasileiros 2013. Rio de Janeiro: IBGE.

Mancini, S. D., Ferraz, J. L., \& Bizzo, W. A. (2012). Resíduos sólidos. In A. H. Rosa, L. F. Fraceto, \& V. Moschini-Carlos (Eds.), Meio ambiente e sustentabilidade (pp. 346-374). Porto Alegre: Bookman.

Nunes, M. R., Philippi, A., Jr., \& Fernandes, V. (2012). Gestão ambiental: objetivos, instrumentos e agentes. Revista Brasileira de Ciências Ambientais, 23, 66-72. Recuperado em 27 de outubro de 2019, de http://rbciamb.com.br/index.php/Publicacoes_RBCIAMB/article/view/333

Oliveira, G., Scazufca, P., \& Pires, R. C. (2018). Ranking do saneamento. São Paulo: Instituto Trata Brasil. Recuperado em 27 de outubro de 2019, de http://www.tratabrasil.org.br/images/estudos/itb/ranking2018/realatorio-completo.pdf.

Philippi, J. R. A., Salles, C. P., \& Malheiros, T. F. (2004). Subsídios para o planejamento estratégico: fortalecimento da gestão ambiental municipal no corredor central da mata atlântica - Bahia. São Paulo: Faculdade de Saúde Pública, Núcleo de Informações em Saúde Ambiental, Universidade de São Paulo.

Rodrigues, W., Magalhães, L. N. L., Fo., \& Pereira, R. S. (2016). Análise dos Determinantes dos custos de resíduos sólidos urbanos nas capitais estaduais brasileiras. urbe. Urbe. Revista Brasileira de Gestão Urbana, 1(8), 130-141. http://dx.doi.org/10.1590/2175-3369.008.001.A002.

Sampaio, R. J., Bonfim, D. A., Santos, J. O., \& Silva, M. F., Jr. (2014). A gestão de resíduos sólidos urbanos: impasses políticos, técnicos, legais e metodológicos. Revista Eletrônica do Mestrado em Educação Ambiental, 2014, 87-101. http://dx.doi.org/10.14295/remea.v31i2.3528.

Scardua, F. P., \& Bursztyn, M. A. A. (2003). Descentralização da política ambiental no Brasil. Sociedade e Estado, 18(1-2), 291-314. http://dx.doi.org/10.1590/S0102-69922003000100014.

Severi, F. C. (2014). Os catadores de materiais recicláveis e reutilizáveis na Política Nacional de Resíduos Sólidos. Revista Direito e Práxis, 5(8), 152-171. http://dx.doi.org/10.12957/dep.2014.9437.

Sistema Nacional de Informações sobre a Gestão dos Resíduos Sólidos - SINIR. (2019). Painel gestão de resíduos sólidos. Recuperado em 27 de outubro de 2019, de http://sinir.gov.br

Sistema Nacional de Informações sobre Saneamento - SNIS. (2019). Diagnóstico dos serviços de resíduos sólidos. Recuperado em 27 de outubro de 2019, de http://app4.cidades.gov.br/serieHistorica/

Souza, C. (2006). Políticas públicas: uma revisão de literatura. Sociologias, 8(16), 20-45. http://dx.doi.org/10.1590/S1517-45222006000200003.

Souza, M. T. S., Paula, M. B., \& Souza-Pinto, H. (2012). O papel das cooperativas nos canais reversos pós-consumo. Revista de Administração de Empresas, 52(2), 246-262. http://dx.doi.org/10.1590/S0034-75902012000200010.

Editor: Harry Bollmann

Recebido: Out. 27, 2019

Aprovado: Ago. 10, 2020 